\title{
A Multivariate Analysis of the 2016 County-Level Presidential Vote and Turnout
}

\author{
Gregg W. Smith \\ University of Tasmania, Data Solutions \\ Jazmin J. Young \\ University of the Sunshine Coast
}

\begin{abstract}
We investigate the 2016 Presidential Election using the county as the unit of analysis to examine the variance in the percentage of votes cast for Clinton, Trump and voter turnout. Our independent variables conceptually relate to race, education, wellbeing, age, rural-urban continuum and international migration. We found that over $50 \%$ of the variance in vote outcome for Clinton and Trump is explained by race, education, economy and the physical health of the county population. Almost $50 \%$ of the variance in voter turnout is explained with the same variables plus age. The regression results showed that Trump voters tended to be more white, less educated, not poor, and unhealthy compared to Clinton voters.
\end{abstract}

Keywords: 2016 Election, 2016 Voter Turnout, County-level Vote 


\section{Introduction}

This research looks at the 2016 county-level presidential vote. ${ }^{1}$ There are 3,141 counties or county equivalents (Boroughs, Parishes, Independent Cities, and 1 District) in the United States. This analysis excludes Alaska due to incompatibility between the vote data and the census data, and one county in Hawaii, Kalawao is excluded due to lack of data; this leaves 3,112 counties or county equivalents. Four additional counties are excluded from the voter turnout data due to the special circumstances within the county, which result in unreliable estimates.

One of the most iconic and widely published images of the 2016 Presidential Election is the blue and red map showing the county vote result (Figure 1) where the redder the colour, the greater the Trump victory and the shades of blue showing the margin of victory for Clinton. It is somewhat ironic that textbooks on the 2016 election (e.g., Schaggner and Clark 2017; Nelson 2017) virtually ignore an analysis of the county vote.

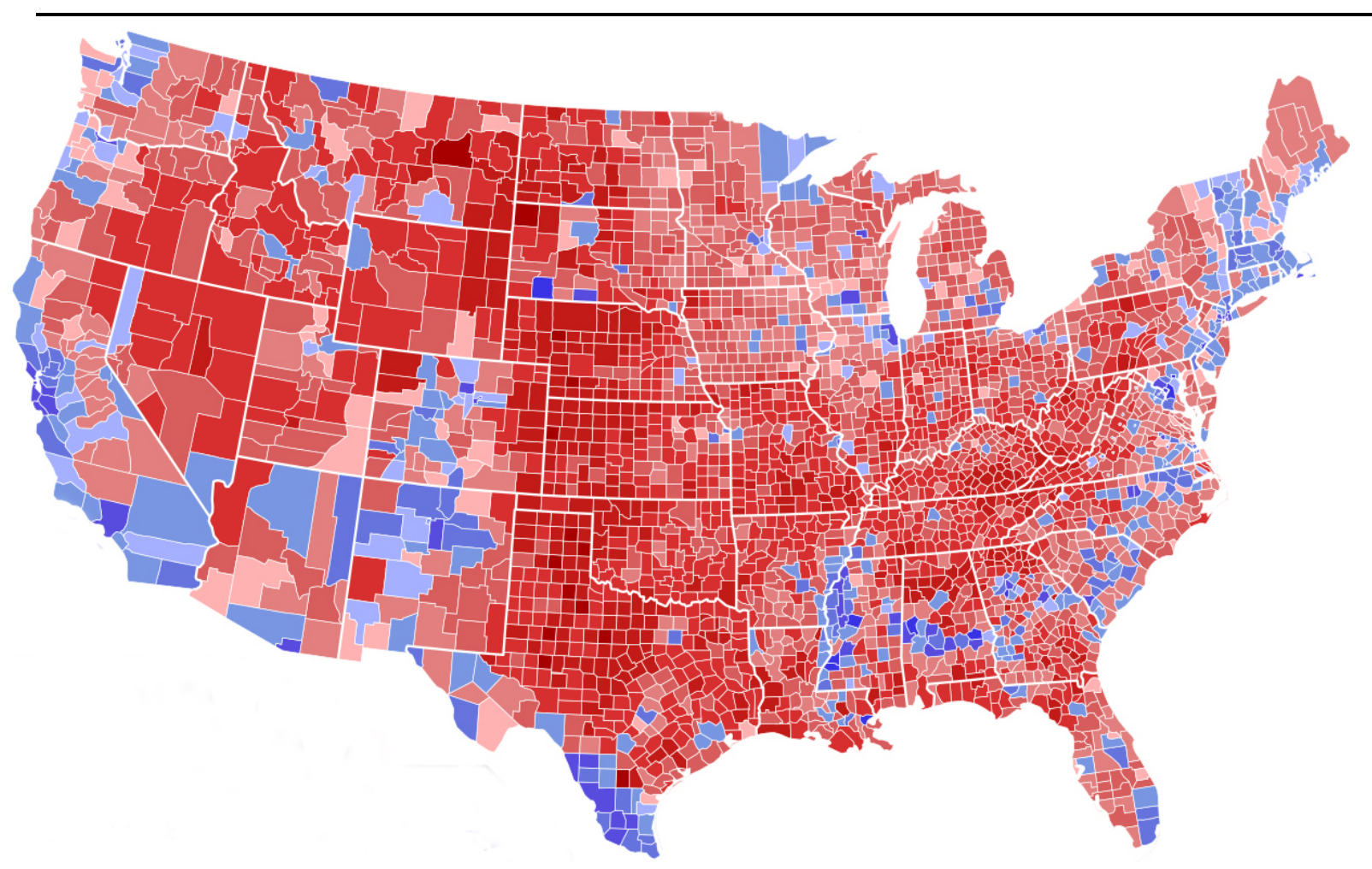

Figure 1: 2016 County Vote Result, Blue (Clinton), Red (Trump) 
Trump won by getting 304 Electoral College votes (57\%) from 30 states, which sounds pretty good until you consider the winner-take-all consequences of elector allocation. ${ }^{2}$ Trump won by barely winning in Michigan, Pennsylvania and Wisconsin. Trump lost the popular vote: 62,984,828 (46.1\%) to Clinton's 65,853,514 (48.2\%), but this also happened in four previous elections (1824, 1876, 1888, and 2000). ${ }^{3}$

In 2016, US counties ranged in population size from 117 (Loving, Texas) to 10,120,540 (Los Angeles, California) with an average population of 103,576. ${ }^{4}$ How many counties did Trump win? Trump got more than $50 \%$ of the vote in 2,503 of the 3,112 counties in this analysis, and he beat Clinton in a further 116 counties with less than $50 \%$ of the vote. Thus, Trump beat Clinton in a whopping $84 \%$ of the counties.

\section{Variable Description}

We're looking at four dependent variables: the precent of the county vote received by Clinton, Trump, other presidential candidates and voter turnout as a percentage of the adult age population. ${ }^{5}$ The independent variables we focus on conceptually relate to race, education, wellbeing, age, the rural-urban continuum and international migration rate:

- Race is operationalized with variables that estimate the percentage of the county that is white, black and Asian (see Devos and Banaji 2005).

- Education is operationalized with variables that estimate the percentage of the county whose highest education level is a high school diploma and the percentage with at least a bachelor's degree.

- Wellbeing is a more complicated concept. In brief, it refers to how well the county population is doing. It is operationalized with estimates for the county poverty rate, median household income, changes in life expectancy between 1985 and 2010, obesity and physical fitness prevalence. ${ }^{6}$

- Age is operationalized with an estimate for the median age of the county population.

- Rural-urban continuum refers to the distribution of the county population (Ghelfi and Parker 1997, 2004). Where the county is located on the continuum determines the availability of goods and services, and opportunities for employment. In this analysis it is operationalized with the estimate of the county population on 1 July $2016 .^{7}$ 
- International migration emerged as an issue in the 2016 election (for background see Citrin et al. 2007). It is operationalized with an estimate for the county’s international migration rate. ${ }^{8}$

Table 1 is a statistical description of the variables in this analysis. Table 2 presents the bivariate Pearson correlations between each of the four dependent variables with the set of the 13 independent variables.

TABLE 1: Descriptive Statistics of Variables

\begin{tabular}{|lrrrr|}
\hline \multicolumn{1}{|c}{ County-Level Variable (2016) } & Mean & Median & \multicolumn{1}{c}{ Std. } \\
Deviation & $N$ \\
Population (number) & 103,576 & 25,910 & 331,993 & 3112 \\
White Population (\%) & 85.12 & 91.84 & 15.92 & 3112 \\
Black Population (\%) & 9.33 & 2.43 & 14.55 & 3112 \\
Asian Population (\%) & 1.44 & 0.68 & 2.64 & 3112 \\
Ed, adults with a high school diploma only (\%) & 34.42 & 34.80 & 7.14 & 3112 \\
Ed, adults with a bachelor's degree or higher (\%) & 21.20 & 19.00 & 9.28 & 3112 \\
Poverty All Ages 2017 (\%) & 15.39 & 14.40 & 6.26 & 3112 \\
Difference in Life Expectancy 1985-2010 (years) & 2.72 & 2.70 & 1.39 & 3112 \\
Physical Activity (fitness) Prevalence (\%) & 51.41 & 51.90 & 6.44 & 3112 \\
Obesity Prevalence (\%) & 38.04 & 37.95 & 4.34 & 3112 \\
International Migration Rate & 1.24 & 0.55 & 2.14 & 3112 \\
Median Household Income (\$) & 50,980 & 48,746 & 13,441 & 3112 \\
Median Age (years) & 42.39 & 42.60 & 5.39 & 3112 \\
Clinton Votes 2016 (\%) & 31.54 & 28.29 & 15.26 & 3112 \\
Trump Votes 2016 (\%) & 63.24 & 66.34 & 15.72 & 3112 \\
Other Votes 2016 (\%) & 5.19 & 4.76 & 3.04 & 3112 \\
Turnout of Voting Age Pop (\%) & 56.89 & 57.21 & 9.34 & 3108 \\
\hline
\end{tabular}

The population of the county is meant to capture the political effect of the rural-urban continuum. Presidential election outcomes (see note 1) have shown that the strength of the Democratic Party has been in large, urbanised areas and the strength of the Republican Party is in smaller, less urban, more rural areas. As expected, population is moderately and positively correlated with the percent of the Clinton vote $(\mathrm{r}=.35)$ and negatively correlated with the Trump percent $(r=-.35)$. County size is virtually uncorrelated with the percent of votes for other candidates and voter turnout. 
Previous research has found a strong relationship between race and vote (e.g., Carmines and Stimson1989; Tate 1991; Leighley 2001; Cook et al. 2017); whiter counties tend to vote Trump $(\mathrm{r}=.52)$ and less for Clinton $(\mathrm{r}=-.59)$. How white the county is has a modest and positive effect on percent of vote for other candidates and turnout. We get similar results in the opposite direction when looking at how black the county is except that such counties are less likely to vote for other candidates $(r=-.42)$. The race divide continues with the Asian population except Asian percentage does not have an impact on other vote or turnout. ${ }^{9}$

TABLE 2: Bivariate Pearson Correlation (r)

\begin{tabular}{|lcccc|}
\hline \multicolumn{1}{|c}{ County-Level Variable (2016) } & $\begin{array}{c}\text { Clinton } \\
\text { Votes }\end{array}$ & $\begin{array}{c}\text { Trump } \\
\text { Votes } \\
\text { (\%) }\end{array}$ & $\begin{array}{c}\text { Other } \\
\text { Votes } \\
(\%)\end{array}$ & $\begin{array}{c}\text { Turnout } \% \\
\text { of Voting } \\
\text { Age Pop }\end{array}$ \\
Population (number) & & & & \\
White Population (\%) & .350 & -.348 & .040 & -.086 \\
Black Population (\%) & -.591 & .519 & .286 & .214 \\
Asian Population (\%) & .518 & -.421 & -.416 & -.135 \\
Ed, adults with a high school diploma only (\%) & .436 & -.448 & .131 & -.083 \\
Ed, adults with a bachelor's degree or higher (\%) & -.412 & .470 & -.355 & -.111 \\
Poverty All Ages 2017 (\%) & .427 & -.486 & .379 & .328 \\
Difference in Life Expectancy 1985-2010 (years) & .411 & -.088 & -.373 & -.487 \\
Physical Activity (fitness) Prevalence (\%) & .128 & -.236 & .567 & .471 \\
Obesity Prevalence (\%) & -.058 & .150 & -.486 & -.384 \\
International Migration Rate & .342 & -.345 & .069 & -.204 \\
Median Household Income (\$) & .177 & -.238 & .345 & .343 \\
Median Age (years) & -.244 & .270 & -.164 & .467 \\
\hline
\end{tabular}

The impact of education level on presidential vote choice was greater in the 2016 election than in previous elections (Galston and Hendrickson 2016). There has been much media commentary claiming that Trump supporters are less educated. This is captured in Table 2 with the two education variables, which have hefty correlations exceeding . 4 and are in the correct direction; that is, counties with relatively high levels of high school diploma only residents tended to vote Trump whereas counties with high levels of college educated people tended to vote Clinton and to a lesser extent, voted for other candidates compared to less educated counties. Note a decent correlation of college educated with turnout $(\mathrm{r}=.33)$. 
There is a modest correlation between age and vote with more aged counties tending to Trump. Consistent with previous research (e.g., Wolfinger and Rosenstone 1980), there is a robust correlation between county age and turnout $(\mathrm{r}=.48)$.

International migration rate is moderately correlated in the expected direction with Clinton/Trump vote; $r=.34, r=-.35$ respectively. It is weakly and negatively correlation with turnout $(\mathrm{r}=-.2)$ and not correlated with vote for other candidate.

Wellbeing is conceptually defined as an overall attitude about how well the county is doing with a perceived linkage to government policy and candidate choice. Public attitudes on economic issues (e.g., Fiorina 1978; Evans and Anderson 2006) such as jobs, wages, taxes; social issues such as crime (e.g., Douglas and Carnes 2012), welfare (e.g., Gilens 2005) environment, immigration (e.g., Citrin et al. 2007), drugs and war (e.g., Grose and Oppenheimer 2007); and service availability and delivery issues such as healthcare, education (e.g. Holbein and Ladd 2015) and transportation will coalesce into a generalised attitude about how well things are going. In theory, if they are going well, there will be a tendency to preserve the status quo, to conserve existing policies, to play it safe. If they are going badly, the public will want change and be willing to take risks in an effort to fix problems. However, different combinations of economic, social and service delivery attitudes, which collapse into a sense of wellbeing that affects vote choice are nuanced, not necessarily linear and dependent upon attitudes about the candidates. As we will see, poverty, an indicator of things not going well and healthy residents, an indicator that things are going well both worked in favour of Clinton.

We operationalized wellbeing with economic and health variables. The economic variables are county poverty rate and median household income. Health related variables have been previously used in political behaviour research (e.g., Söderlund and Rapeli 2015; Pacheco and Fletcher 2015; Burden et al. 2017; Ksiazkiewicz 2020). We believe that when things are going well economically, socially and in service delivery, it will result in good health outcomes for the county population; as such, health statistics can be used as an indicator of wellbeing. The ones we use are the change in life expectancy from 1985 to 2010 (Wang et al. 2013), the percentage of the county population that is obese and the percentage of the county that meets minimum physical activity guidelines (Dwyer-Lindgren et al. 2013).

The Table 2 correlations for poverty and the dependent variables show that poverty is the best predictor for voter turnout $(r=-.49)$, has a moderate correlation with votes for other 
candidates ( $\mathrm{r}=$-.37) but is weakly correlated in the expected direction with Clinton and Trump votes. One could surmise that since poor people are less likely to vote, their effect on vote choice will be depressed. For median household income, the correlations with Clinton and Trump vote are larger than poverty but remain weak and indicate that wealthy counties tended (weakly) to go Clinton.

With the health related correlations, changes in life expectancy has a strong impact on Clinton/Trump votes, $\mathrm{r}=.41$ and $\mathrm{r}=-.43$ respectively. Physical activity and obesity are strong predictors of vote for other candidates and turnout (see Burden et al. 2017). They are the two best predictors of vote for other candidates and are the $3^{\text {rd }}$ and $4^{\text {th }}$ best predictors of turnout after poverty and age. They have weak correlations in the expected direction for Clinton/Trump votes.

If you extrapolate the bivariate correlations to describe a typical Trump voter, one could say that they are older white people from non-metro areas with few international migrants who are neither rich nor poor (concurs with Cook et al. 2017), are less educated, do not have healthy lifestyles as they are more obese, less physically fit and have shorter expected lifespans than Clinton voters.

\section{Regression Analysis}

We wanted to see how this set of 13 independent variables would fare if they were regressed against each of the four dependent variables and used SPSS software (version 22) to do that. Using stepwise regression with forward entry, the criterion selected is the probability ( $p$ ) of the F-ratio to enter the model must be significant at $p \leq .01$ level and $p \geq .05$ level to be removed. ${ }^{10}$

The following tables describe the results of the regression analysis for each of the four dependent variables. The independent variables are listed in the order that they were entered. The standardised beta coefficients $(\beta)$ are for the final model. The betas can be compared to each other; the larger the absolute value of the beta, the greater the influence of the variable. The adjusted $R^{2}$ is cumulative. ${ }^{11}$ For example in Table $3, R^{2}$ is .35 in the first step when white population is entered and rises to .53 when adults with a bachelor's degree is added to white population in the second step. The adjusted $R^{2}$ can be interpreted as the percent of the variance in the dependent variable that is explained by the independent variables. 


\section{Clinton Vote}

Table 3 presents the results of the regression analysis for the percent of the Clinton vote as the dependent variable. The percentage of the white population is entered on the first step because that variable had the highest bivariate correlation with the Clinton vote percentage (see Table 2). At this point the $\beta$ is the same as the bivariate correlation (-.59), which when squared, is .35 so $35 \%$ of the variance in the Clinton vote is explained by percent of white population. On the next step, the algorithm looks at all the other variables after the effect of white population has been partialed out (or controlled for) and selects the next one with the highest partial correlation, which is adults with at least a bachelor degree. The betas are then recalculated because there are now two variables in the equation and the $R^{2}$ value rises to .53 . This process continues until there are no more significant variables to enter as determined by the probability of the F-ratio criterion $(p \leq .01)$.

TABLE 3: Clinton County Vote (\%)

\begin{tabular}{|lcc|}
\hline \multicolumn{1}{|c}{ County-Level Variable (2016) } & Beta $\beta$ & Adjusted $R^{2}$ \\
White Population (\%) & -.175 & .349 \\
Ed, \% of adults with a bachelor's degree or higher & .327 & .532 \\
Difference in Life Expectancy 1985-2010 (years) & .166 & .559 \\
Poverty \% All Ages 2017 & .243 & .581 \\
Population (number) & .089 & .591 \\
International Migration Rate & .080 & .596 \\
Black Population (\%) & .280 & .602 \\
Physical Activity (fitness) Prevalence \% & .269 & .612 \\
Obesity Prevalence \% & .184 & .618 \\
Asian Population (\%) & .106 & .623 \\
& & \\
Note: The significance of the t values for all regression coefficients is p $<.0001$. \\
\end{tabular}

Of the 13 independent variables that were considered, 10 of them were significant enough to be entered into the equation (listed in Table 3); age, household income and adults with only a high school education were not significant after the effects of the significant variables were controlled for. We can see from the $\beta$ values that college educated adults has the greatest impact on the Clinton vote (.33) followed by, black population (.28), physical fitness (.27) and poverty 
(.24). Collectively, these 10 independent variables account for $62 \%$ of the variance in the Clinton vote.

\section{Trump Vote}

Table 4 presents the results when the percent of the Trump vote is the dependent variable. The first four variables entered are the same that were entered in Table 3 (Clinton vote) and the value of the betas are similar except, of course, the direction (+ or -) is reversed. Of the 13 variables considered, 11 were statistically significant including median age which is not in the Clinton model. Collectively, the independent variables account for about $60 \%$ of the variance in the Trump vote. For Trump the variable that has the greatest impact is lack of physical fitness (.37) followed by the lack of college education (-.34), absence of poverty (-.23) and absence of black people (-.20), which are the same most important variables in the Clinton model but in a different order.

TABLE 4: Trump County Vote (\%)

\begin{tabular}{|lcc|}
\hline \multicolumn{1}{|c}{ County-Level Variable (2016) } & Beta $\beta$ & Adjusted $R^{2}$ \\
White Population (\%) & .197 & .269 \\
Ed, \% of adults with a bachelor's degree or higher & -.338 & .506 \\
Difference in Life Expectancy 1985-2010 (years) & -.142 & .530 \\
Poverty \% All Ages 2017 & -.234 & .547 \\
Physical Activity (fitness) Prevalence \% & -.370 & .564 \\
International Migration Rate & -.070 & .573 \\
Population (number) & -.081 & .579 \\
Obesity Prevalence \% & -.190 & .587 \\
Black Population (\%) & -.203 & .591 \\
Asian Population (\%) & -.090 & .595 \\
Median Age & .045 & .596 \\
Note: The significance of the t values for all regression coefficients is $\mathrm{p}<.0001$ \\
except median age which is $\mathrm{p}<.0007$.
\end{tabular}

\section{Discussion of the Clinton/Trump Regression Results}

In both models, the percent of the population whose highest education level is completing high school and the median income of the county are not significant variables when considered alongside the other variables. This is because high school education and college education are 
highly correlated as are poverty and median household income, both of which are $\mathrm{r}=-.77$ so once the best one is entered, the residual variance of the other one is not significantly correlated with the dependent variable.

Thus, education level was important and the percent of college educated is the best predictor. The health of the population was important and the precent who get the minimal amount of exercise to be healthy is the best predictor. Race was important and the best predictor is the percentage of the black population. The economy was important and the best predictor is the poverty rate. Most of the other variables in the model are related to health or race. International migration, size of the county and age hardly had any impact at all once education, health, poverty and race are entered into the equation. It's not that those variables were unimportant as they all have significant bivariate correlations with Clinton/Trump vote but rather they become unimportant when the variance they share with other variables is removed.

Table 5 shows the regression results for Clinton/Trump vote when just the four best variables are entered: black population percent, percent of population with at least a bachelor's degree, poverty rate, and the percent of the population who meet a minimum level of physical activity to be healthy.

TABLE 5: Regression Results for Most Significant Independent Variables

\begin{tabular}{|c|c|c|}
\hline Variable (percent of population) & Clinton Vote Betas & Trump Vote Betas \\
\hline Black People & $\beta=.520$ & $\beta=-.453$ \\
\hline At least a Bachelor's Degree & $\beta=.466$ & $\beta=-.477$ \\
\hline Poverty Rate & $\beta=.280$ & $\beta=-.289$ \\
\hline Meets Minimum Level of Physical Activity & $\beta=.235$ & $\beta=-.314$ \\
\hline Adjusted R squared & $R^{2}=.544$ & $R^{2}=.522$ \\
\hline
\end{tabular}

\section{Other Presidential Candidate Vote}

Table 6 is the regression result for votes other than Clinton or Trump as the dependent variable. The problem with looking at this relates to the fact that votes cast for other candidates were on average only about $5.2 \%$ of the county vote; thus, the variance is constrained. In 
addition, the vote for other candidates is dispersed among 20 parties plus independents. ${ }^{12}$ Of the 13 independent variables, 8 were found to be statistically significant; poverty, household income, obesity, population, and college education were not significant at the .01 level.

The regression results in Table 6 are for the three best predictors of votes cast for other candidates: percent of county that meet minimal level of physical activity, median age and the precent of black people. Thus, “other votes” tend to come from counties that are more physically fit, younger and with fewer black people.

TABLE 6: Other Candidate Vote (\%)

\begin{tabular}{|c|c|c|}
\hline County-Level Variable (2016) & Beta $\beta$ & Adjusted $R^{2}$ \\
\hline Physical Activity (fitness) Prevalence \% & .495 & .321 \\
\hline Median Age & -.269 & .377 \\
\hline Black Population (\%) & -.256 & .430 \\
\hline \multicolumn{3}{|c|}{$\begin{array}{l}\text { Note: The significance of the } t \text { values for all regression coefficients is } \\
\qquad p<.0001 \text {. }\end{array}$} \\
\hline
\end{tabular}

\section{Voter Turnout}

All of the 13 independent variables were significantly related to county voter turnout at the .01 level. However, on the $10^{\text {th }}$ step of the regression process, white population percent was removed as the significance of its F-ratio became greater than .05. The 12 significant variables accounted $56 \%$ of the variance in voter turnout.

Table 7 shows the regression results for the five most important independent variables. As in the previous regression tables, the variables are listed in the order that they were entered, the betas are for the final model and the adjusted $R^{2}$ is reported for each step. The median age of the county has the greatest impact on turnout, which is consistent with a large body of existing research (e.g., Wolfinger and Rosenstone 1980; Gerber and Rogers, 2009; Rogers, Fox, and Gerber 2013); older people vote more than younger people. The next highest beta is poverty and is negative, which is to say that as the poverty rate increases, turnout declines. These two variables together explain about $40 \%$ of the turnout variance. After age and poverty, the next best predictor of voter turnout is the wellbeing physical fitness variable, which is the precent of the county population that meets the minimum level of physical activity to be considered healthy 
(see Pacheco and Fletcher 2015). When you control for poverty, the percent of the county’s black population has a significant and positive effect but it is a small effect (see Fraga 2016a, 2016b; Tate 1991). The same is true for the percent of those with at least a bachelor's degree. While the highly educated do vote more (bivariate $r=.33$ ), when the effects of the other variables are partialed out, the effect remains positive and statistically significant but it is relatively small.

TABLE 7: County Voter Turnout (\%)

\begin{tabular}{|lcc|}
\hline \multicolumn{1}{|c}{ County-Level Variable (2016) } & Beta $\beta$ & Adjusted $R^{2}$ \\
Poverty \% All Ages 2017 & -.311 & .236 \\
Median Age & .464 & .400 \\
Ed, \% of adults with a bachelor's degree or higher & .165 & .459 \\
Black Population (\%) & .193 & .474 \\
Physical Activity (fitness) Prevalence \% & .205 & .493 \\
Note: The significance of the t values for all regression coefficients is $\mathrm{p}<.0001$.
\end{tabular}

\section{Discussion of the Wellbeing Variables}

We have argued that the concept of the wellbeing of the county helps to explain the 2016 election results. We operationalized that concept with two economic and three health variables. Previous research has shown the value of using health related, i.e., physiological variables as predictors of political behaviour (e.g., Madsen 1985, 1986; Söderlund and Rapeli 2015; Pacheco and Fletcher 2015; Burden et al. 2017; Ksiazkiewicz 2020). Table 8 shows the high multicollinearity of the three health related variables and poverty. ${ }^{13}$

The regression analysis for all the dependent variables has shown that of the health related wellbeing variables, the percent of the county that meets the minimum healthy level of physical activity is the best of these inter-correlated variables. That is, it shares the most variance with the dependent variables after the effects of the other variables have been controlled for (partialed out). Because of the shared variance between these variables, once one of them is entered into a multiple regression model, it will be hard for the others to be significant unless they retain enough residual variance with the dependent variable. 
Nevertheless, even though there is a strong correlation between poverty and physical fitness is $(r=-.60)$, physical fitness is still a significant predictor of the Clinton, Trump and voter turnout dependent variables after poverty has been entered into the equation (both variables are on the short list of best predictors). The physical fitness of the county is capturing something that poverty does not in explaining voter choice and turnout.

TABLE 8: Pearson Correlations of the Health Related Variables and Poverty

\begin{tabular}{|c|c|c|c|c|}
\hline $\begin{array}{l}\text { Inter-correlations of the } \\
\text { health related variables } \\
\text { and poverty. }\end{array}$ & $\begin{array}{c}\text { Poverty All } \\
\text { Ages (\%) }\end{array}$ & $\begin{array}{l}\text { Difference in } \\
\text { Life } \\
\text { Expectancy } \\
\text { (years) }\end{array}$ & $\begin{array}{l}\text { Physical } \\
\text { Activity } \\
\text { Prevalence } \\
\text { (\%) }\end{array}$ & $\begin{array}{l}\text { Obesity } \\
\text { Prevalence } \\
\quad(\%)\end{array}$ \\
\hline Poverty All Ages (\%) & 1 & -.398 & -.600 & .624 \\
\hline $\begin{array}{l}\text { Difference in Life } \\
\text { Expectancy (years) }\end{array}$ & -.398 & 1 & .498 & -.453 \\
\hline $\begin{array}{l}\text { Physical Activity } \\
\text { Prevalence (\%) }\end{array}$ & -.600 & .498 & 1 & -.832 \\
\hline Obesity Prevalence (\%) & .624 & -.453 & -.832 & 1 \\
\hline
\end{tabular}

Even with the very high correlation between physical fitness and obesity $(r=-.83)$, both are still significant predictors in the Clinton, Trump and Turnout equations at the .01 level. Indeed, all of the variables in Table 8 are in the long list of statistically significant variables for each of the dependent variables except the vote for a candidate other than Clinton or Trump. But when short-listing the best predictors for explaining the Clinton and Trump vote and voter turnout, only the precent of the county that is poor and the precent who meet the minimum healthy level of physical activity are included as the others do not contribute enough additional explained variance to be justified. 


\section{Summary}

Trump overwhelmingly beat Clinton at the county-level by winning $84 \%$ of the 3,112 counties in this study, which examined four dependent variables with thirteen independent variables. Over $50 \%$ of the variance in the percent of the county vote cast for Clinton and Trump is explained by race, education, economy and the physical health of the county population. Almost 50\% of the variance in county turnout is explained with the same variables plus age, which has the greatest affect. The regression results showed that Trump voters tended to be more white, less educated, not poor, and unhealthy compared to Clinton voters.

The best predictor of race in a multivariate analysis with multicollinearity is the percent of the county's black population. The best predictor for education under the same circumstances is the percent of residents with at least a bachelor's degree. Likewise, the best predictor for the wellbeing concept related to the economy is the poverty rate, and for residential health it is the percent of the population that meets the minimum level of physical activity to be healthy.

\section{Endnotes}

${ }^{1}$ County 2016 vote for president source: MIT Election Data and Science Lab. (2018). County Presidential Election Returns 2000-2016. https://doi.org/10.7910/DVN/VOQCHQ.

${ }^{2}$ All states except Maine and Nebraska give the candidate with the most votes all of the state's electors. This tends to inflate the size of the electoral vote of the winning candidate.

${ }^{3}$ Source: Federal Election Commission, Federal Elections 2016; December 2017, https://www.fec.gov/introduction-campaign-finance/election-and-voting-information/federal-elections2016/.

${ }^{4}$ Unless otherwise noted, 2016 county population characteristics are sourced from the Census Bureau: Annual Estimates of the Resident Population for Counties in 2016. (June, 2019). U.S. Census Bureau, Population Division. https://www.census.gov/programs-surveys/decennialcensus/data/datasets.2016.html.

${ }^{5}$ The 2016 adult population includes the estimated 6,106,327 adults who cannot vote because of felony convictions (see Gerber et al., 2017).

${ }^{6}$ The three health related variables are sourced from the Center for Disease Control and Prevention, https://www.cdc.gov/nccdphp/dnpao/index.html.

${ }^{7}$ For an alternative measure and more discussion on the rural-urban concept see the US Department of Agriculture https://www.ers.usda.gov/data-products/rural-urban-continuum-codes.aspx. 
${ }^{8}$ For a discussion on the economics of international migration in the US, see “Delayed Reaction”. The Economist, February 15, 2020: 19-20.

${ }^{9}$ In 2016 America, there were 986 counties in which the population was at least 95\% white. There were also 100 counties in which the population was at least $50 \%$ black.

${ }^{10}$ We have taken into consideration the criticism of this approach by Lewis-Beck (1978). For a specification of the exact mathematical procedure, see SPSS Reports (1985), 165-75.

${ }^{11}$ This format does not apply to Table 5.

12 The Libertarian Party (3.3\% of national vote), Greens Party US (1\% of the national vote) and the Constitution Party of the United States were the ones with the greatest ballot access.

${ }^{13}$ Median household income was not a significant variable in either the Clinton or Trump equations.

\section{References}

Arnold, R. Douglas, and Nicholas Carnes. 2012. “Holding Mayors Accountable: New York’s Executives from Koch to Bloomberg.” American Journal of Political Science 56 (4): 949-63. https://doi.org/10.1111/j.1540-5907.2012.00603.x.

Burden, Barry C., Jason M. Fletcher, Pamela Herd, Bradley M. Jones, and Donald P. Moynihan. 2017. "How Different Forms of Health Matter to Political Participation" The Journal of Politics 79 (1): 166-78. https://doi.org/10.1086/687536.

Carmines, Edward G., and James A. Stimson. 1989. Issue Evolution: Race and the Transformation of American Politics. Princeton, NJ: Princeton University Press.

Citrin, Jack, Amy Lerman, Michael Murakami, and Kathryn Pearson. 2007. “Testing Huntington: Is Hispanic Immigration a Threat to American Identity?” Perspectives on Politics 5 (1): 31-48. https://doi.org/10.1017/s1537592707070041.

Cook, Alexander C., Nathan J. Hill, Mary I. Trichka, Grace J. Hwang, and Paul M. Sommers. 2017. “Who Voted for Trump in 2016?” Open Journal of Social Sciences 5 (7): 199-210. https://doi.org/10.4236/jss.2017.57013.

Devos, Thierry, and Mahzarin R. Banaji. 2005. “America =White?” Journal of Personality and Social Psychology 88 (3):447-66. https://doi.org/10.1037/0022-3514.88.3.447.

Dwyer-Lindgren, Laura, Greg Freedman, Rebecca E. Engell, Thomas D. Fleming, Stephen S. Lim, Christopher J. L. Murray, and Ali H. Mokdad. 2013. "Prevalence of physical activity and obesity in US counties, 2001-2011: a road map for action”. Population Health Metrics 11: 7. https://doi.org/10.1186/1478-7954-11-7. 
Evans, Geoffrey, and Robert Anderson. 2006. “The Political Conditioning of Economic Perceptions.” Journal of Politics, 68 (1): 194-207. https://doi.org/10.1111/j.1468-2508.2006.00380.x.

Fiorina, Morris P. 1978. "Economic Retrospective Voting in American National Elections: A MicroAnalysis.” American Journal of Political Science 22 (2): 426-43. https://doi.org/10.2307/2110623.

Fraga, Bernard L. 2016a. "Redistricting and the Causal Impact of Race on Voter Turnout.” The Journal of Politics 78 (1): 19-34. https://doi.org/10.1086/683601.

Fraga, Bernard. 2016b. "Candidates or Districts? Reevaluating the Role of Race on Voter Turnout.” American Journal of Political Science 60 (1): 97-122. https://doi.org/10.1111/ajps.12172.

Galston, William A., and Clara Hendrickson. 2016. “The educational rift in the 2016 election.” Brookings Institution. https://www.brookings.edu/blog/fixgov/2016/11/18/educational-rift-in-2016-election/.

Gerber, Alan S., and Todd Rogers. 2009. "Descriptive Social Norms and Motivation to Vote: Everybody’s Voting and So Should You.” The Journal of Politics 71 (1): 178-91. https://doi.org/10.1017/s0022381608090117.

Gerber, Alan S., Gregory A. Huber, Marc Meredith, Daniel R. Biggers, and David J. Hendry. “Does Incarceration Reduce Voting? Evidence about the Political Consequences of spending Time in Prison”. 2017. The Journal of Politics 79 (4): 1130-46. https://doi.org/10.1086/692670.

Ghelfi, Linda M., and Timonthy S. Parker. 1997. "A County-Level Measure of Urban Influence." Rural America / Rural Development Perspective, United States Department of Agriculture, Economic Research Service 12 (2). DOI: 10.22004/ag.econ.278818.

Ghelfi, Linda M., and Timonthy S. Parker. 2004. "Using the 2003 Urban Influence Codes To Understand Rural America.” United States Department of Agriculture, Economic Research Service. https://www.ers.usda.gov/amber-waves/2004/april/using-the-2003-urban-influence-codes-tounderstand-rural-america/.

Gilens, Martin. 2005. Why Americans hate welfare: Race, media, and the politics of antipoverty policy. Chicago, IL: University of Chicago Press.

Grose, Christian R., and Bruce I. Oppenheimer. 2007. "The Iraq War, Partisanship, and Candidate Attributes: Variation in Partisan Swing in the 2006 US House Elections.” Legislative Studies Quarterly 32 (4): 531-57. https://doi.org/10.3162/036298007782398495.

Holbein, John, and Helen F. Ladd. 2015. “Accountability Pressure and Non-Achievement Student Behaviors.” Calder Working Paper No. 122. https://caldercenter.org/publications/accountabilitypressure-and-non-achievement-student-behaviors.

Ksiazkiewicz, Aleksander. 2020. "Conservative Larks, Liberal Owls: The Relationship between Chronotype and Political Ideology." The Journal of Politics 82 (1): 367-71. https://doi.org/10.1086/705927. 
Leighley, Jan E. 2001. Strength in Numbers? The Political Mobilization of Racial and Ethnic Minorities. Princeton, NJ: Princeton University Press.

Lewis-Beck, Michael S. 1978. “Stepwise Regression: A Caution.” Political Methodology 5 (2): 213-40. https://www.jstor.org/stable/25791533.

Madsen, Douglas. 1985. “A Biochemical Property Relating to Power-Seeking in Humans.” American Political Science Review 79 (2): 448-57. https://doi.org/10.2307/1956659.

Madsen, Douglas. 1986. “Power Seekers are Different: Further Biochemical Evidence.” American Political Science Review 80 (1): 261-69. https://doi.org/10.2307/1957094.

Nelson, Michael (editor). 2018. The Elections of 2016. Thousand Oaks, Canada: SAGE Publications.

Pacheco, Julianna, and Jason Fletcher. 2015. "Incorporating Health into Studies of Political Behavior: Evidence for Turnout and Partisanship.” Political Research Quarterly 68: 104-16. https://doi.org/10.1177/1065912914563548.

Rogers, Todd, Craig R. Fox, and Alan S. Gerber. 2013. “Rethinking Why People Vote.” In The Behavioral Foundations of Public Policy, ed. Eldar Shafir, 91-107. Princeton, NJ: Princeton University Press.

Schaggner, Brian and John A. Clark. 2018. Making Sense of the 2016 Elections. Thousand Oaks, Canada: SAGE Publications.

Söderlund, Peter, and Lauri Rapeli. 2015. "Personal Health and Political Participation in the Nordic Countries.” Politics and the Life Sciences 34: 28-43. https://doi.org/10.1017/pls.2015.3.

SPSS Reports. 1985. “Regression.” In SPSS Statistical Algorithms, 165-75. Chicago, IL: SPSS Inc.

Tate, Katherine. 1991. "Black Political Participation in the 1984 and 1988 Presidential Elections.” American Political Science Review 85 (4): 1159-76. https://doi.org/10.2307/1963940.

Wang, H., A. E. Schumacher, C. E. Levitz, A. H. Mokdad, and C. J. Murray. 2013. "Left behind: widening disparities for males and females in US county life expectancy, 1985-2010.” Population Health Metrics 11:8. https://doi.org/10.1186/1478-7954-11-8.

Wolfinger, Raymond E., and Steven J. Rosenstone. 1980. Who Votes? New Haven, CT: Yale University Press. 